\title{
AN ANALYSIS OF THE LIQUID FILMS BREAK-UP USING THE COMPUTER VISION TECHNIQUE
}

\author{
LuCIE MĚŠŤANOVÁ*, OndŘEJ BARTOŠ
}

\author{
Czech Technical University in Prague, Faculty of Mechanical Engineering, Department of Energy Engineering, \\ Technická 4, 16607 Prague 6, Czech Republic \\ * corresponding author: lucie.mestanova@fs.cvut.cz
}

Abstract. The aim of this paper is to introduce a novel approach for analysing the droplet formation in a transonic flow. The method suggested in this work is based on the combination of the measured data from the wind tunnel by an optical measurement and image processing. A new wind tunnel was developed for the study of the liquid film atomization at high speed flows similar to ones that can be found in steam turbines. The coarse droplets in steam turbines are formed from the liquid films on the blades and inner casings. The coarse droplets formed on the stator blades don't follow the bulk flow and collide with the following moving blades. These collisions cause erosion and corrosion processes, which have an unfavourable effect on the reliability and the efficiency of the low pressure stages of steam turbines. The tunnel is equipped with a standard instrumentation for the measurement of the flow properties and for the analysis of the size distribution of the droplets. Two measurement methods were used for the measurement of the size of the droplets, photogrammetry and light scattering. In this paper, the image processing of the captured images is discussed. The images were taken by a camera with a telecentric lens. The paper contains an assessment of three image processing methods used for the measurement of the droplet distribution by the light extinction. Moreover, the formation of the droplets is captured on the trailing edge of the profile in the flow. The results bring a new view on the formation of droplets at high speeds.

KeYwords: Coarse droplet, liquid film, steam turbine.

\section{INTRODUCTION}

The liquid film disruption is an important topic in the field of aerosol research [1], but a general solution for different engineering applications is still missing. Water film disruption is known to occur in steam turbines. The coarse droplets formed from the films on blades and casings are related with undesirable effects on the reliability and efficiency of steam turbines [2, 3]. One can mention effects like additional energy losses, blades erosion or reduction of blades' life-time. The study of liquid atomization, movement and further impact on the moving blades of turbines at a high speed has an important role in the never-ending effort to enhance the energy production efficiency and decrease its environmental impact. As an example of other practical applications where liquid films are involved, the effect of rain on wind turbines and airplane wings could be mentioned. Nevertheless, due to the wide range of engineering applications of the liquid film break-up, this paper is focused on the conditions in steam turbines. The Energy engineering Department at CTU is involved in the experimental research of wet steam in steam turbines for several decades [4]6].

In steam turbines, two significant groups of droplets can be distinguished as a result of the fast steam expansion under the saturation line. The droplets' nucleation and the ensuing growth due to the surface condensation are responsible for the presence of fine droplets. Their assumed diameter range is between
$50 \mathrm{~nm}$ and $800 \mathrm{~nm}$. Coarse droplets are formed by water film break-up from the blades and casing surfaces in the low-pressure turbine stages of fossil fuels power stations. In the nuclear (PWR) steam cycles, they can be observed on the entire turbine. Their diameter range can be very wide, from few micrometres to one millimetre. The present knowledge about a coarse droplets' flow field and their size distribution in turbines is still insufficient. A better understanding of their formation and properties may provide a future enhancement for steam turbines and other similar applications. Previous measurements of coarse droplets directly in the steam turbine made it necessary to build an experimental tunnel for the study of droplets' formation and their properties [4] in the laboratory. In the literature, several studies of the liquid film disruption at high speeds exist but without any quantitative analysis [1].

This paper contains a description of the wind tunnel, used optical measurement methods and an assessment of three image processing methods for different parameters of the camera's setting to get the most convenient combination for the purpose of the measurement. The goal was to compare the water amount swept from an aerofoil's trailing edge between the image processing and the light scattering measurement. The image processing of the acquired images was performed in Matlab environment. 


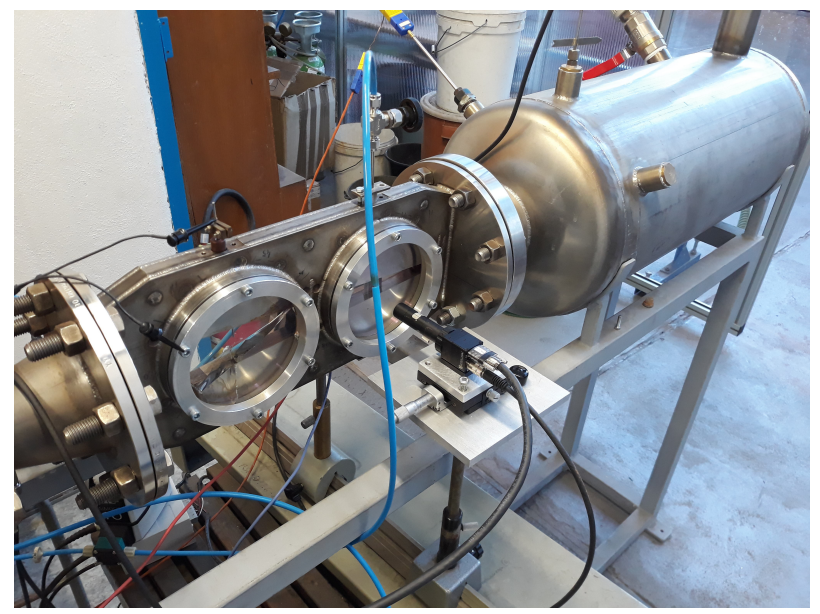

Figure 1. Wind tunnel test section.

\section{Methodology}

\subsection{Testing EQUiPMEnT}

The reason to build the new wind tunnel arose from previous measurements [4] of the coarse droplets in the working steam turbine. The measurements were performed in three steam turbines in Czech Republic in recent years. The quantity of the acquired coarse droplets was very low due to their relative low density. The difficulties related with measurements inside steam turbines led to the return to laboratory measurements. The wind tunnel was designed and manufactured for the analysis of the formation of coarse droplets from the liquid films. An important goal of the design was to emulate the tunnel flow conditions in the steam turbine as closely as possible together with the advantages of working in a laboratory [7].

The flow part of the wind tunnel is a classical convergent divergent $(\mathrm{CD})$ nozzle, but the common operational regime is mainly subsonic or transonic. A symmetrical NACA0008 aerofoil was placed $50 \mathrm{~mm}$ behind the nozzle throat (Fig. 1). The aerofoil simulates the blade of the turbine and it is possible to remove or replace it. The CFD simulation (Fig. 2) of the flow in the wind tunnel was performed in order to have better knowledge of the flow field in the nozzle. The results of the simulation presented in the paper [8] show a complex flow field where in some regions, mainly behind the aerofoil, the velocity exceeds the speed of sound but in vicinity of the blade, the flow is subsonic. On the aerofoil, there is a small gap for supplying liquid on its surface. The liquid is pumped with a constant volumetric flow to the aerofoil through the dosing pump with a flow from $1 \mathrm{ml} / \mathrm{min}$ to $500 \mathrm{ml} / \mathrm{min}$. The tunnel is equipped with four large optical windows to provide a good view of the measuring chamber. It is possible to operate the tunnel with steam in a continuous mode or with compressed air in a periodic mode.

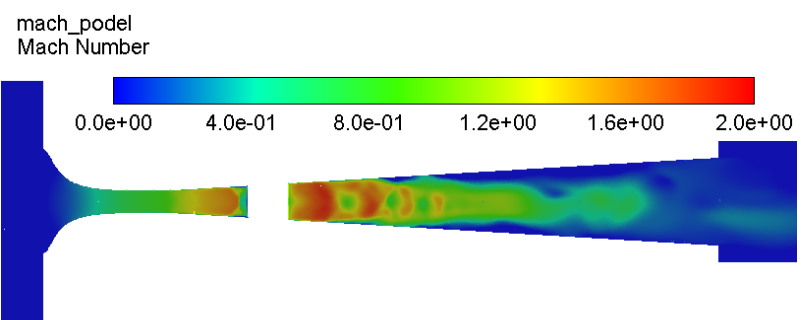

Figure 2. Mach number distribution in the nozzle in a longitude cross section (inlet stagnation pressure $200 \mathrm{kPa}$ ) 8.

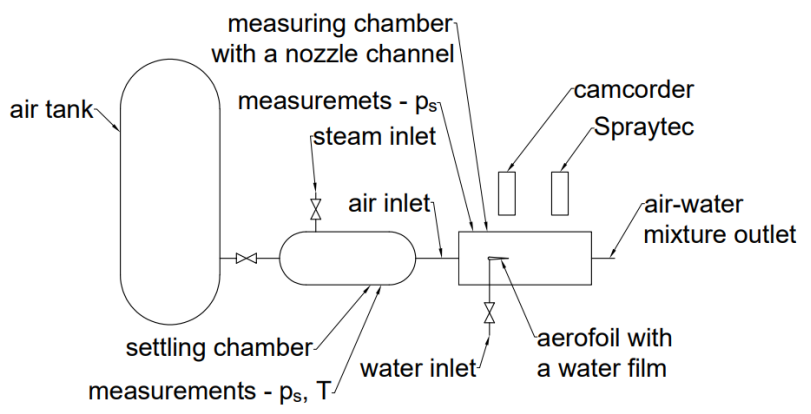

Figure 3. Measurement schema of the nozzle.

\subsection{Measurement method}

The wind tunnel is connected with the compressed air storage vessel or to the steam supply grid. The volume of the storage vessel determines the duration of a single measurement and pressure determines the flow regime in the nozzle. The pressure and temperature of an entire measurement sequence is acquired by the measurement system for the flow conditions description.

Two optical methods of droplets' size measurement are available. The light scattering method is used for small particles and photogrammetry [3] is used for bigger droplets and also for formation of droplets on the aerofoil trailing edge. The measurement schema is shown in Fig. 3

The considered diameter range of coarse droplets in steam turbines is between $1 \mu \mathrm{m}$ to $1 \mathrm{~mm}$ and a similar range is expected for the nozzle. This wide range is almost impossible to measure with a single optical method. That is the reason for the two different optical methods. These methods can cover the whole range with sufficient overlapping.

The light scattering measurement is performed by the commercial measurement device Spraytec (Malvern Ins.). Light scattering is a method for determining mainly fine particles forming on the aerofoil trailing edge. The size of fine particles is under the measurability limit of the photogrammetry method. Light scattering method also serves as a backup measurement system.

Photogrammetry is a method for determining the object properties from captured images by the camera. The camera XIMEA MC050CG-SY was used. 
It contains colour CMOS digital image sensor Sony IMX250 LQR-C. The sensor has $2464 \times 2056$ active pixels on a $3.45 \mu \mathrm{m}$ pitch. The theoretical resolution is determined by the pixel pitch and the magnification of the lens. The lens resolution, the sensor spatial resolution and the light wavelength limit the system's optical resolution. The spatial resolution of the used digital image can be expressed in the unit of line pairs per $\mathrm{mm}(\mathrm{lp} / \mathrm{mm})$. According to Nyquist-Shannon sampling theorem, the finest resolvable frequency at the focal plane is $1 /(2 \cdot 0.00345)=145 \mathrm{lp} / \mathrm{mm}$ for the $3.45 \mu \mathrm{m}$ pitch. The magnification is limited by the minimum exposure time of the camera when the global shutter is used and the time of illumination. In the case of the measurement in the wind tunnel, a flash light with a short flash is used. The duration of the flash is in order of microseconds. The measurement was made with $2 \times$ magnifying telecentric lens, which provides the advantage that the image size is independent of the distance from the lens. For an assessment of the smallest resolvable distance in the object plane $\Delta l$, the Rayleigh's criterion can be used:

$$
\Delta l \approx 1.22 \lambda \frac{1}{1+|m|} w F / \#
$$

For $w F / \#=17.3, \lambda=533 \mathrm{~nm}$ and $m=2$, the smallest resolvable distance $\Delta l=3.75 \mu \mathrm{m}$. In the focal plane with $2 \times$ magnification, the theoretical maximum diffraction determined resolution would be $1 /(0.00375) / 2=133 \mathrm{lp} / \mathrm{mm}$ [9]. The velocity of the droplets can reach more than $300 \mathrm{~m} / \mathrm{s}$ in the steam turbine and in the wind tunnel, it is possible to reach even higher velocities. The droplet velocity and the minimum exposure or illumination time define the size of the observed volume. The entire observed volume must be imaged on the camera sensor and this requirement limits the magnification of the lens. This means that each droplet is presented as a line on the picture. Path length and exposure time allows the droplet velocity to be calculated and the expected droplet direction to be determined. It is necessary to realize that the view of the motion is two-dimensional. This means that one can see only the velocity elements perpendicular to the camera axis. The depth of the observed volume is determined by the field depth of the lens.

A calibration is required for a correct pixel/dimension ratio. The ratio was determined with the help of the calibration target (Fig. 4) of $1.7 \mu \mathrm{m} / \mathrm{px}$. The light source with a variable length of the flash at the order of $0.5-17 \mu$ s was used.

\subsection{DATA PROCESSING}

The time dependent measurement of the pressure and temperature provides sufficient information to describe the flow field in the nozzle. The captured images show the droplet formation process and from the light scattering measurement, the size distribution function of the droplets is available. Due to the

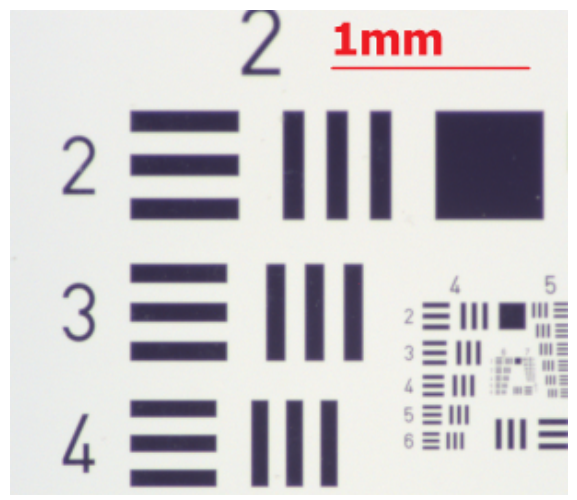

Figure 4. Calibration target.

stochastic process of the formation of droplets on the trailing edge, the desired general solution requires a large number of measurements and statistical data processing for different conditions. These measurements are not available yet, but the current results should be considered as a promising beginning. The typically used non-dimensional parameter for the formation of droplets is the Weber number (2), defined as the ratio between the dynamic forces and the surface tension.

$$
W e=\frac{\rho_{g} w_{r}^{2} d}{\sigma}
$$

where $\rho_{g}$ is the vapour density, $\sigma$ is the surface tension of the water, $w_{r}$ is the relative velocity between vapour and the droplets and $d$ is the diameter of the droplets.

To determine an average particle size, typical Sauter mean diameter was used, defined as the diameter of a sphere that has the same volume/surface area ratio as a particle of interest.

$$
d_{32}=\frac{\sum d_{v}^{3}}{\sum d_{s}^{2}}
$$

where $d_{v}$ is the volume diameter and $d_{s}$ is the surface diameter of the droplets 10 .

\subsection{Captured images}

All the images show the side of the aerofoil where the water injection is. The images present the trailing edge and the region just behind the trailing edge. The window is approximately $3.5 \times 4 \mathrm{~mm}$. Both RGB and BW images were captured. The images were captured under following conditions: the stagnation pressure in the air storage vessel was 2.5 bar and the flow of the dosing pump was set to $1 \mathrm{ml} / \mathrm{min}$. Fig. 5 shows an example of a captured image. All images show a similar formation process.

In the literature, is possible to find many image processing methods for the automatic identification of the objects on the image. A few segmentation methods were chosen for the obtained images herein. In particular, the following methods were tested for the liquid identification on each image: a clustering method, a thresholding method and an active contour method. These methods are briefly presented below. 


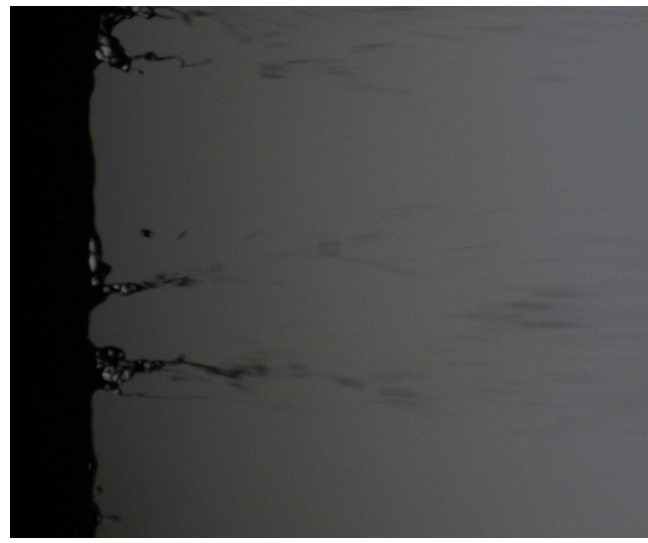

FIGURE 5. An example of captured image.

\subsubsection{Clustering method - Gaussian Mixture MODEL (GMM) BASED METHOD}

The method is using the custom area labelling to denote both foreground (area of interest) and background (the rest) of the image. The marking of foreground and background is essential for a proper segmentation. This method was found suitable for the RGB images. To interpret probabilities of the pixel colour $x_{t} \in[0,1]^{3}$ under the labels two GMMs (Gaussian Mixture Model) are used. Gaussian Mixture Model is a continuous distribution. The Ddimensional GMM with K-components is defined by:

$$
\begin{aligned}
\sum_{k=1}^{K} \phi_{k} N\left(x ; \mu_{k}, \Sigma_{k}{ }^{\circ}\right) & = \\
= & \sum_{k=1}^{K} \frac{\phi_{k}}{(2 \pi)^{D}\left|\Sigma_{k}\right|} e^{-\frac{1}{2}\left(x-\mu_{k}\right)^{T} \Sigma_{k}^{-1}\left(x-\mu_{k}\right)} \\
p_{y}\left(x_{t}\right)=p\left(x_{t}, \theta_{y}\right) & = \\
& =\sum_{k=1}^{K} \phi_{y, k} N\left(x_{t} ; \mu_{y, k}, \Sigma_{y, k}\right)
\end{aligned}
$$

where $\phi_{k}$ is a prior probability, $\mu_{y, k}$ is the mean vector, $\Sigma_{k}$ is the covariance matrix, $N\left(x ; \mu_{k}, \Sigma_{k}^{\circ}\right)$ is the multivariate normal distribution in the D-dimension. Both GMMs are fully specified by a set of their parameters:

$$
\theta_{y}=\left\{\phi_{y, 1} \ldots \phi_{y, K}, \mu_{y, 1} \ldots \mu_{y, K}, \Sigma_{y, 1} \ldots \Sigma_{y, K}\right\}
$$

There is a hidden variable $c_{t} \in\{1 \ldots K\}$, referring which component generated $x_{t}$. Then it holds:

$$
\begin{gathered}
p\left(x_{t} ; \theta_{1}\right)=\sum_{c=1}^{K} p\left(x_{t}, c ; \theta_{1}\right)= \\
=\sum_{c=1}^{K} p\left(x_{t} \mid c ; \theta_{1}\right) p\left(c ; \theta_{1}\right)= \\
\quad=\sum_{c=1}^{K} N\left(x_{t}, \mu_{1, c}, \Sigma_{1, c}\right) \phi_{1, c}
\end{gathered}
$$

$K$-means algorithm is used to estimate $c_{t} \in\{1 \ldots K\}$ for each pixel $t \in T_{1}$. This means that all pixels from $T_{1}$ are divided into $K$ clusters. $C_{1, k}$ is a set of all pixels from $T_{1}$ which were classified in cluster $k$.

$$
C_{1, k}=\left\{t \mid t \in T_{1}, c_{t}=k\right\}
$$

Then, the parameters of the set $\theta_{y}$ are found by MLE (maximum likelihood estimation):

$$
\begin{gathered}
\phi_{1, k}=\frac{\left|C_{1, k}\right|}{\left|T_{1}\right|} \\
\mu_{1, k}=\frac{1}{\left|C_{1, k}\right|} \sum_{t \in C_{1, k}} x_{t} \\
\Sigma_{1, k}=\frac{1}{\left|C_{1, k}\right|} \sum_{t \in C_{1, k}}\left(x_{t}-\mu_{1, k}\right)^{T}\left(x_{t}-\mu_{1, k}\right)
\end{gathered}
$$

When we have both GMMs, it is possible to classify the rest of the pixels in the image as:

$$
\begin{aligned}
y_{t}=\arg \max _{y \in\{1,2\}} p\left(x_{t} ; \theta_{y}\right)= \\
=\arg \max _{y \in\{1,2\}} \sum_{k=1}^{K} \phi_{y, k} N\left(x_{t} ; \mu_{y, k}, \Sigma_{y, k}\right)
\end{aligned}
$$

2.4.2. Thresholding Method - Otsu's Method Thresholding methods, in general, are simple segmentation methods. They are suitable for BW images. An image histogram is usually used in order to find/estimate/select a threshold(s), which divide an image into two (or more) parts.

According to Otsu's method, two thresholds were found so the image was split into three parts. Subsequently, the "middle" part was rewritten to the "first" one to achieve more accurate result of the segmentation.

Otsu's method supposes the pixels in an image being represented in $L$ gray levels. Every level i contains ni pixels, the total number of pixels is $N=n_{1}+n_{2}+$ $\cdots+n_{i}$. The gray-level histogram is considered as a probability distribution:

$$
p_{i}=\frac{n_{i}}{N}, \quad p_{i} \geq 0, \quad \sum_{i=1}^{L} p_{i}=1
$$

The pixels are supposed to be dichotomized into two classes $C_{0}$ and $C_{1}$ - foreground and background, by a threshold at level $k$. Then, the probabilities of class occurrence:

$$
\begin{gathered}
\omega_{0}=\operatorname{Pr}\left(C_{0}\right)=\sum_{i=1}^{k} p_{i}=\omega(k) \\
\omega_{1}=\operatorname{Pr}\left(C_{1}\right)=\sum_{i=k+1}^{L} p_{i}=1-\omega(k)
\end{gathered}
$$

and the class mean levels:

$$
\mu_{0}=\sum_{i=1}^{k} i \operatorname{Pr}\left(i \mid C_{0}\right)=\sum_{i=1}^{k} i \frac{p_{i}}{\omega_{0}}=\frac{\mu(k)}{\omega(k)}
$$




$$
\mu_{1}=\sum_{i=k+1}^{L} i \operatorname{Pr}\left(i \mid C_{1}\right)=\sum_{i=k+1}^{L} i \frac{p_{i}}{\omega_{1}}=\frac{\mu_{T}-\mu(k)}{1-\omega(k)}
$$

where $\omega(k)=\sum_{i=1}^{k} p_{i}$ is the zeroth-order cumulative moment of the histogram, $\mu(k)=\sum_{i=1}^{k} i p_{i}$ is the first-order cumulative moment of the histogram, $\mu_{T}=$ $\mu(L)=\sum_{i=1}^{L} i p_{i}$ is the total mean level of the original image.

Otsu's method deals with discriminant criterion measures in the discriminant analysis. For more details, see [11]. The optimal threshold value $k^{*}$ is selected by maximizing the function $\sigma_{B}^{2}$ :

$$
\sigma_{B}^{2}(k)=\frac{\left[\mu_{T} \omega(k)-\mu(k)\right]^{2}}{\omega(k)[1-\omega(k)]}
$$

so the optimal threshold $k^{*}$ is:

$$
\sigma_{B}^{2}\left(k^{*}\right)=\max _{1 \leq k<L} \sigma_{B}^{2}(k)
$$

For finding two thresholds (our case), it is necessary to add one class $C_{2}$, then the thresholds $k_{1}^{*}$ and $k_{2}^{*}$ are derived from:

$$
\sigma_{B}^{2}\left(k_{1}^{*}, k_{2}^{*}\right)=\max _{1 \leq k_{1}<k_{2}<L} \sigma_{B}^{2}\left(k_{1}, k_{2}\right)
$$

\subsection{Active COntour Method - "ChAN - VESE" METHOD}

The image segmentation can be performed by active contour methods also called "snakes". Their essential idea is to evolve a curve that moves towards its interior. Based on a specific term, the curve stops on the boundary of the desired object. Most of these methods use a stopping term depending on the gradient of the image.

"Chan - Vese" is a region-based method and it is suitable for grayscale images [12] or for colour and multi-channel images [13. Its great advantage is that this method can detect the object in a noisy image without very smooth edges. The authors introduced the energy functional $F\left(c_{1}, c_{2}, C\right)$ as:

$$
\begin{aligned}
& F\left(c_{1}, c_{2}, C\right)=\mu \cdot \text { Length }(C)+v \cdot \text { Area }(\text { inside }(C))+ \\
& +\lambda_{1} \int_{\text {inside }(C)}\left|u_{0}(x, y)-c_{1}\right|^{2} d x d y+ \\
& +\lambda_{2} \int_{\text {outside }(C)}\left|u_{0}(x, y)-c_{2}\right|^{2} d x d y \quad \text { (19) }
\end{aligned}
$$

where $u_{0}$ denotes the image consisting of two regions with approximatively piecewise-constant intensities, the constants $c_{1}, c_{2}$ depending on curve $C$ are the averages of $u_{0}$ inside $C$ and outside $C$, respectively, and fixed parameters $\mu \leq 0, v \leq 0, \lambda_{1}, \lambda_{2}>0$. Then, they considered the minimization problem:

$$
\inf _{c_{1}, c_{2}, C} F\left(c_{1}, c_{2}, C\right)
$$

Sparse-Field level set formulation [14] is used for solving the minimization problem.

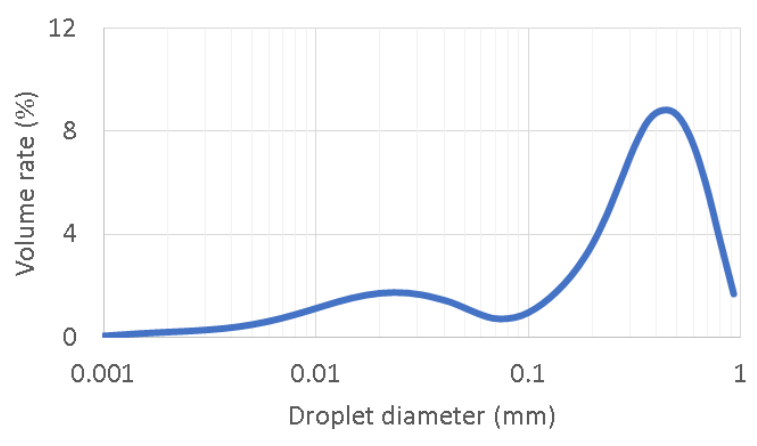

FiguRE 6. Volumetric distribution of the droplets.

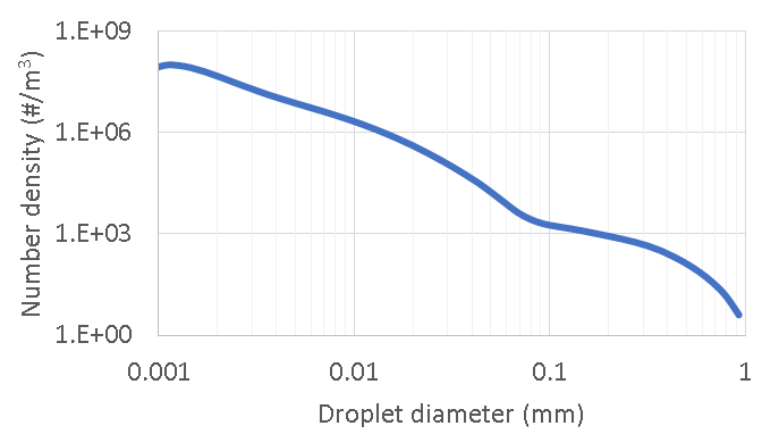

FiguRE 7. Number density distribution of the droplets.

\section{EXPERIMENTAL RESULTS}

\subsection{Size Distribution AND AERODYNAmics}

Optical (light scattering) measurement device Spraytec was used for the measurements of the size distribution function of the swept droplets behind the aerofoil. Fig. 6 shows the volumetric distribution and Fig. 7 shows the corresponding number density distribution for the same measurements. Volumetric distribution with an expected constant density of the water can be considered as a mass distribution function.

The bi-modal distribution shown in Fig. 6 is clearly visible for all measurements. The lines represent the mean values of 7 measurements (same conditions: 2.5 bar and $1 \mathrm{ml} / \mathrm{min}$ ). The first modus refers to approximately $40 \mu \mathrm{m}$ and the second to $400 \mu \mathrm{m}$. The Weber number for the first modus is around $W e=10$, while for the second one it is more than $W e=100$. The Weber number was determined with respect to the velocity profile in the nozzle. Fig. 8 shows the pressure and velocity profiles during a typical measurement. As one can see, the velocity is almost constant during the measurement. This is caused by the aerodynamics blockage in the nozzle throat. Fig. 7 shows the number density distribution. It is necessary to realize that the number density is different in comparison with the mass distribution. Due to the existence of the bi-modal size distribution, the data of the size distribution function were divided into two groups and for both groups, the Sauter mean diameter was computed separately. The edge diameter between 


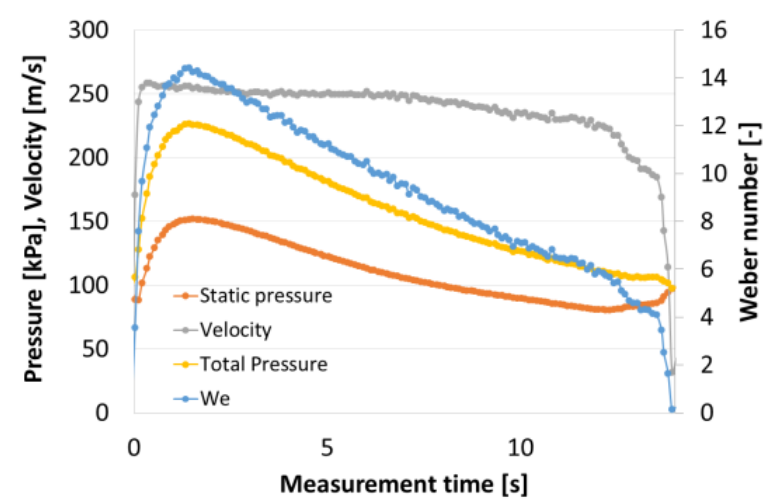

Figure 8 . The typical time profile of the pressures and velocity during measurement in the nozzle behind the aerofoil.

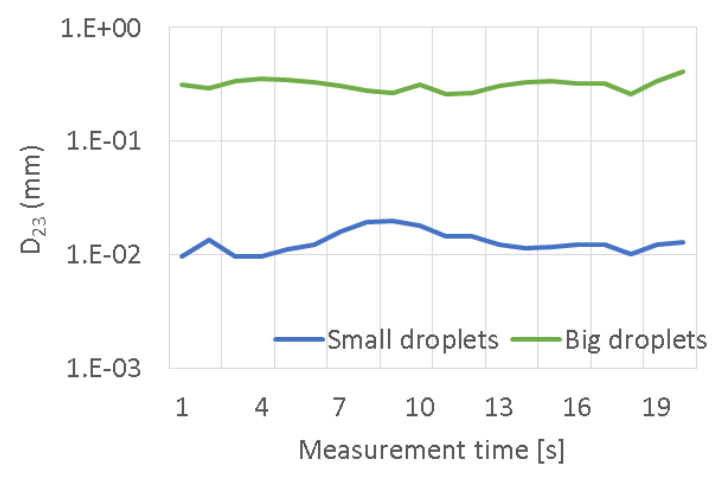

Figure 9. Time evolution of the Sauter mean diameter during the measurement.

"small" and "big" droplets was chosen at $60 \mu \mathrm{m}$. The droplets from first group have a significantly smaller impact on the erosion process, and even though the distribution slightly changes, the threshold value for the classification of small and big droplets is kept the same (even though it is not always within the minimum of the total distribution). Fig. 9 presents the time dependence of the Sauter mean diameter for both groups. One can see that the Sauter mean diameter is almost constant throughout the measurement.

\subsection{Photographic EXPERIMENTS}

This section is divided into two parts. The first part is devoted to colour images and their segmentation, while second part is devoted to grayscale images and their segmentation. The segmentation was performed in Matlab environment.

Segmented images resulting from the GMM-based segmentation give the lowest number of foreground pixels. This method can detect droplets, but its computational time is long and the necessity of labelling definition makes this method unsuitable.

Active contour method doesn't work very well for grayscale images. However, for colour images, it gives better result than the GMM-based method. The computational time of this method is acceptable. Its advantage could be that it is easy to use.

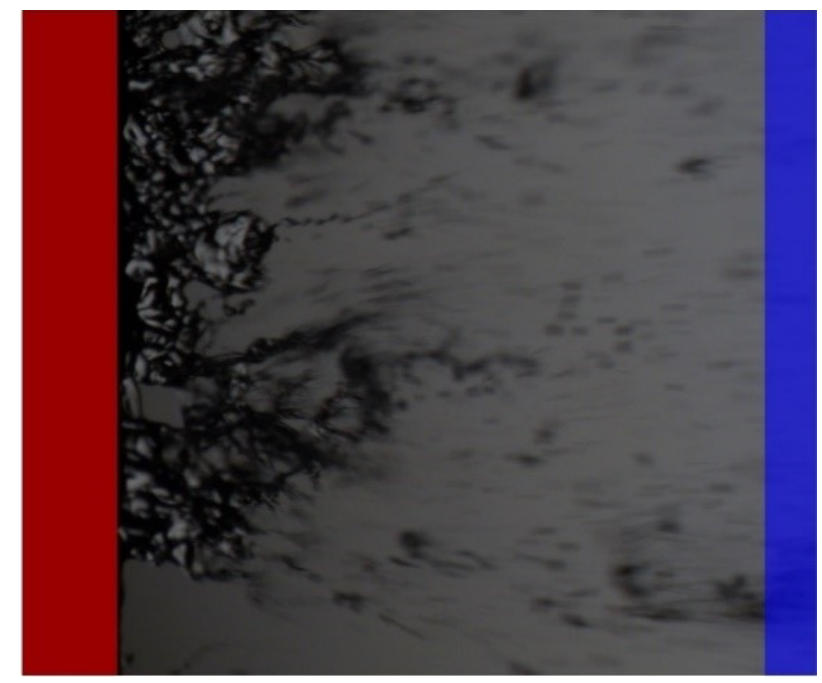

Figure 10. Captured image with labelling.

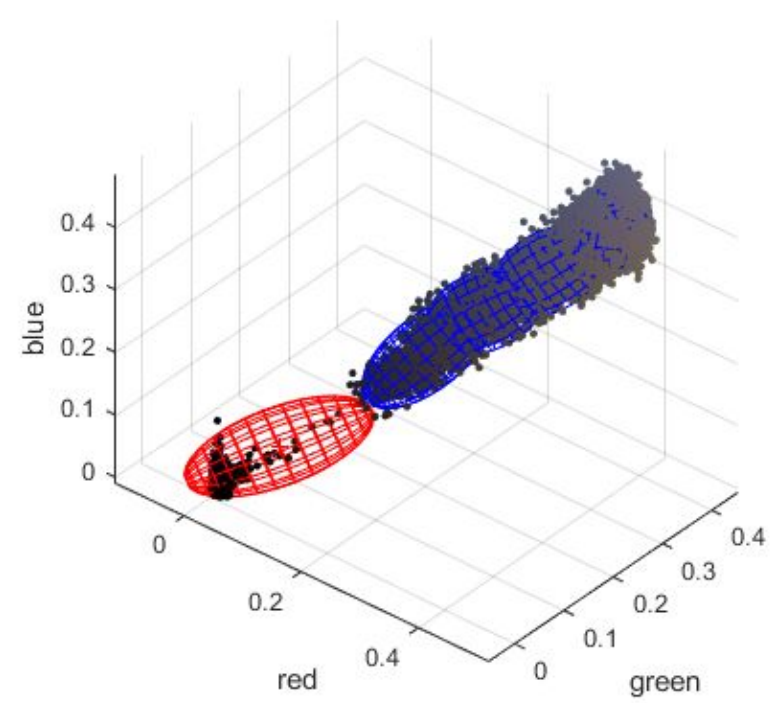

Figure 11. The sample RGB values and estimated GMMs.

Otsu's method gives the best results. This method can also detect droplets and its greatest advantage is the fast computational time and easy handling.

The computational time for different images is very variable. For example, the arbitrary set of 14 images, which were segmented, can be mentioned. Otsu's method needed approximately 50 second per image, active contour method needed, on average, 3 minutes and 20 second and the GMM-based method needed more than 14 minutes for just one image segmentation.

\subsubsection{Colour images SEgmentation}

Three segmentation methods are compared here GMM-based method, active contour method and Otsu's method. Otsu's method is suitable only for grayscale images, so our colour images had to be transferred to a grayscale for the comparison purposes.

GMM-based segmentation needs to define the foreground and the background. Fig. 10 presents the original image with the labelling. A red stripe defines 


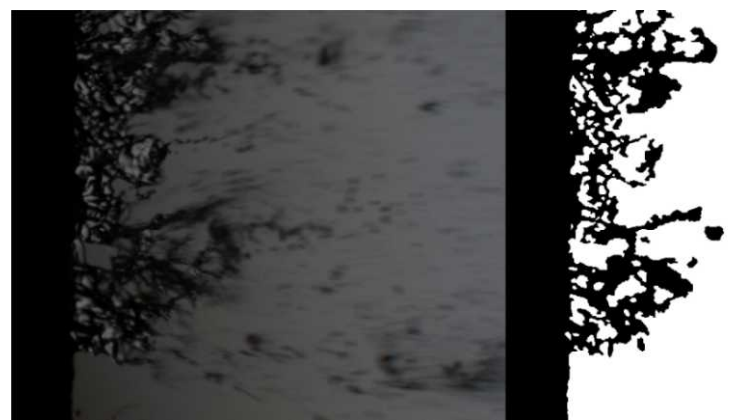

Figure 12. Original (left) and segmented (right) image using GMM-based method.

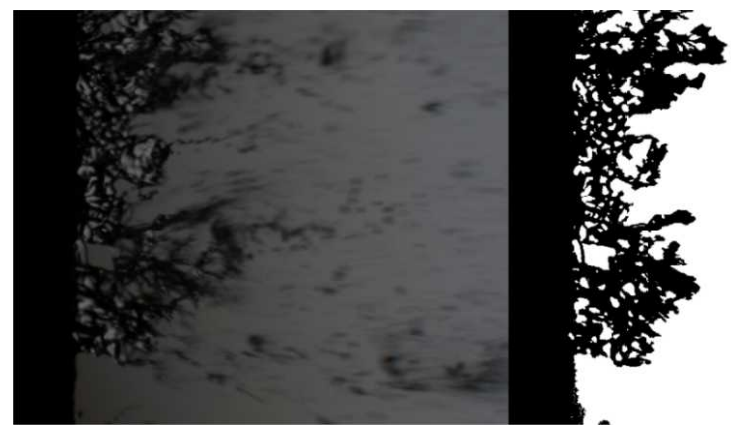

FiguRE 13. Original (left) and segmented (right) image using active contour method.

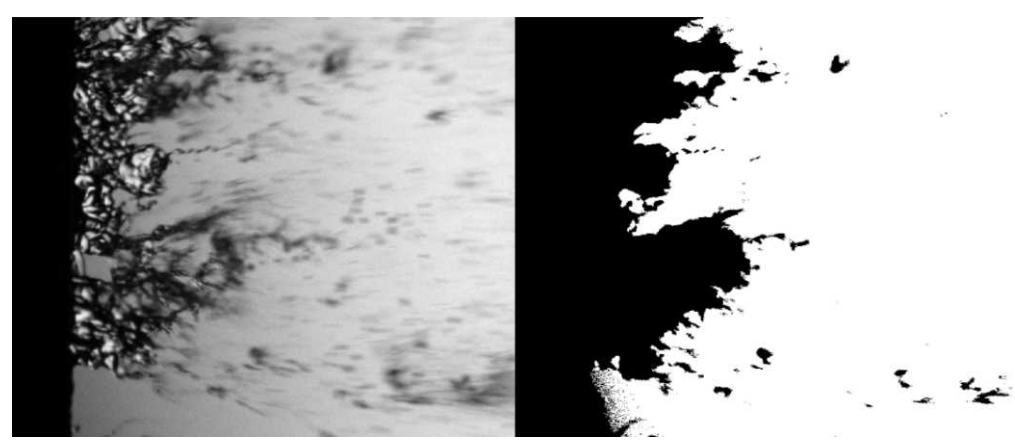

Figure 14. Original (left) and segmented (right) image using Otsu's method.

the foreground and a blue stripe defines the background of the image. The aerofoil with the water is considered as the foreground.

Fig. 11 depicts the plot of the RGB values denoted by the labelling from Fig. 10 and their estimated GMMs distributions.

Each of Fig. 12, Fig. 13 and Fig. 14 shows an original colour image on the left side and its segmented version on the right side. More examples of both grayscale and colour segmented images are in the appendix of this paper.

Fig. 15 shows the number of segmented pixels from each colour image. For the analysis, the set of the 6 images was used, all the images are from one run of the nozzle. The active contour and GMM-based methods give almost identical number of segmented pixels, but Otsu's method gives several times higher number of segmented pixels, corresponding to the images of Fig. 12 - 14 All curves have a similar shape, but Otsu's method identifies more droplets in all images.

\subsection{Grayscale images SEgmentation}

This part is devoted to grayscale images. Two segmentation methods are compared here - the Otsu's method and the active contour method. Within the measurement of grayscale images, temperature and pressures were also measured. For the images shown in Fig. 16 and Fig. 17, flow parameters were: stagnation temperature $15^{\circ} \mathrm{C}$, stagnation pressure $200 \mathrm{kPa}$.

Thus, Fig. 16 and Fig. 17 show an original grayscale image on the left side and its segmented version on the right side. The active contour method fails to provide a satisfactory result.

Fig. 18 shows the number of segmented pixels from each grayscale images. In this case, the same set of images was used as the colour segmentation. Unlike colour images, the curves don't have a similar shape, but Otsu's method is, again, more representative. 


\section{Color images segmentation}

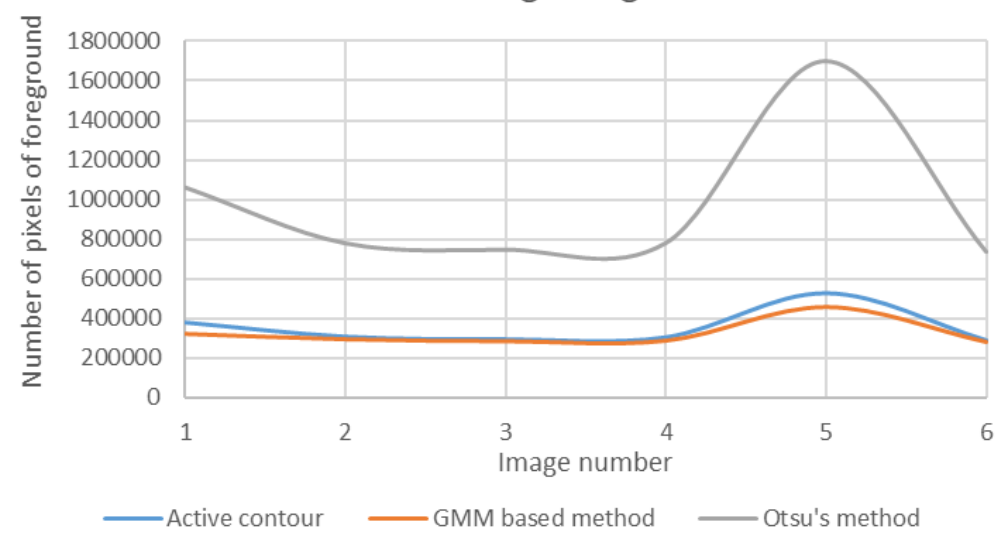

FiguRE 15. Number of segmented pixels from colour images.

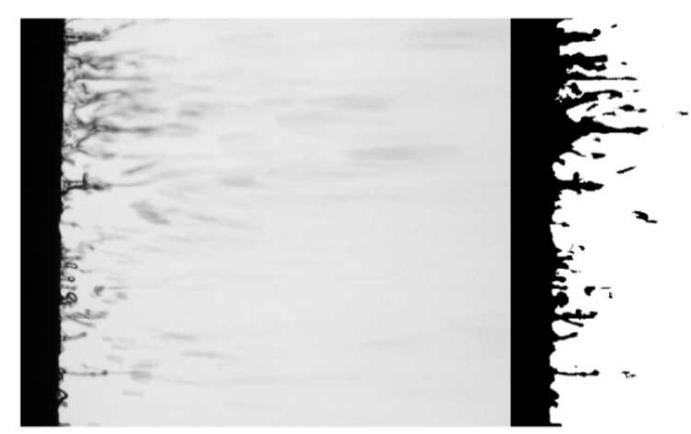

Figure 16. Original (left) and segmented (right) image using Otsu's method.

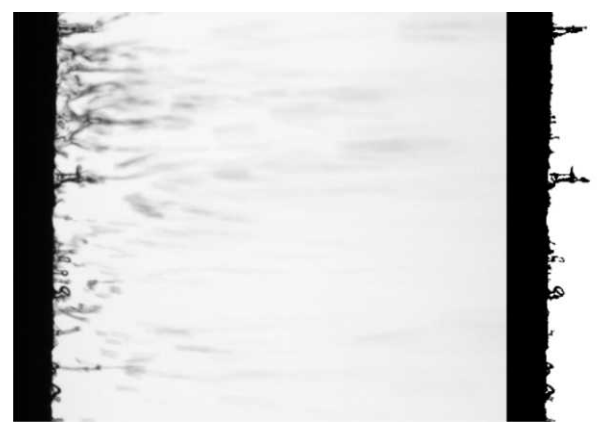

Figure 17. Original (left) and segmented (right) image using active contour method.

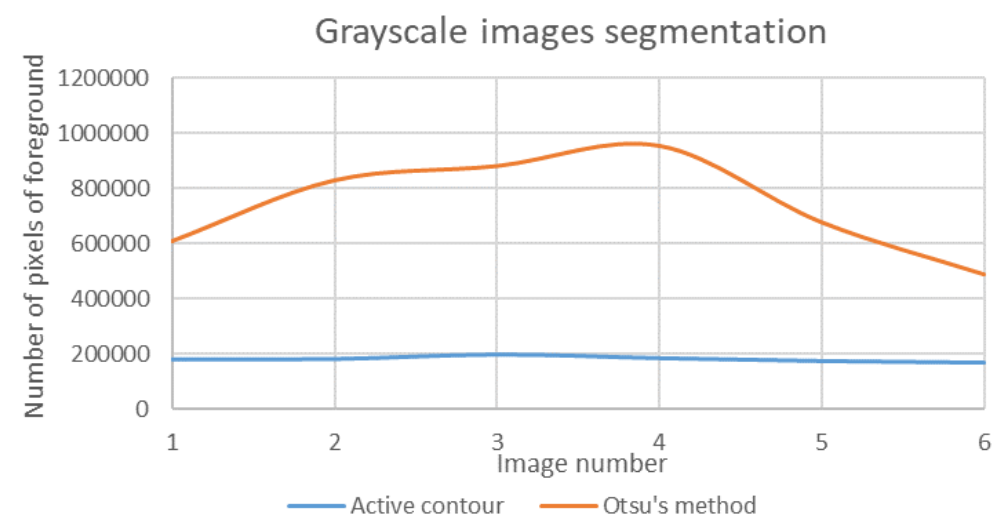

FiguRE 18. Number of segmented pixels from grayscale images. 


\section{Discussion}

This paper presents measurements of the number of droplet breakups. By the application of the two optical measurement methods, a bi-modal size distribution was found in all observations. In previous works [15, 16. a critical Weber number of approximately $20-40$ was found, which indicates the biggest formed droplet by the gas liquid interaction in high Mach number flows. This was not proved herein because the biggest droplets had a Weber number within hundreds.

The bi-modal droplet size distribution is a novel information for the estimation of the erosion process in a steam turbines. Nowadays the steam turbines are mostly not working in the design regime and an off-design operation mode leads to a higher wetness of the output steam, this means more liquid in the low pressure part of the turbine. The erosion model should be modified for a better prediction of the blade's life time.

The observation of the trailing edge of the testing profile shows several regimes of the water sweeping from the tiny filaments to the chaotic process that, in the literature, is mentioned as the catastrophic breakup [17. The acquired data show that the theoretical solution of the liquid breakup needs a statistical solution and for these purposes, computer vision techniques seem to be a sufficient tool. At the moment, the computer vision proves the existence of the second mode of the droplets distribution and shows the structures of the liquid on the trailing edge. The best method for this analysis could be the Otsu's method.

This information about the process on the trailing edge is important for the manufacturer of the turbines for the design of the erosion model [18].

\section{Conclusions}

The series of the measurements in the wind tunnel brought the valuable information about the liquid film breakup at a transonic regime. The images from the photogrammetric method show a stochastic process (catastrophic breakup) on the trailing edge of the testing profile. Together with the measurement using the light scattering method, the size distribution function of the produced droplets is known and can be used for further analyses. Three methods of the image segmentation were tested to determine the amount of the water on the image and the size distribution function of the droplets in the vicinity of the trailing edge of the profile. The chaotic process behind the trailing edge is not generally possible to be described and due to this, further study is required.

The image processing methods are suitable for the analysis. The best results were obtained by the Otsu's method. Moreover, this method has the lowest computation time.

The main conclusion from the entire measurement is the production of the bi-modal size distributions of the atomized droplets. Further measurement will include different aqueous solutions and Ma numbers will be performed.

The future work will be focused on the description of the liquid film breakup. A general solution is probably far away, but with the application of a statistical approach, one could find a dependence on the flow parameters, liquid film thickness and chemical composition of the liquid.

\section{ACKNOWLEDGEMENTS}

We gratefully acknowledge the support by the National Centre for Energy TN01000007 and the Grant Agency of the Czech Technical University in Prague, Grant No. SGS $13 / 18$.

\section{REFERENCES}

[1] Z. Farago, N. Chigier. Parametric experiments on coaxial airblast jet atomization. In ASME 1990 International Gas Turbine and Aeroengine Congress and Exposition. American Society of Mechanical Engineers Digital Collection, 1990. DOI:10.1115/90-GT-081.

[2] G. Gyarmathy, H. Meyer. Spontane Kondensation, VDI-Forschungsheft Verein Deutscher Ingenieure 508, chap. Part 2: Versuche über den Einfluß der Entspannungsschnelligkeit auf die Nebelbildung in übersättigtem Wasserdampf, p. 31-48. VDI-Verlag, Düsseldorf, 1965.

[3] V. Petr, M. Kolovratník. Wet steam energy loss and related Baumann rule in low pressure steam turbines. Proceedings of the Institution of Mechanical Engineers, Part A: Journal of Power and Energy 228(2):206 - 215, 2014. DOI:10.1177/0957650913512314

[4] O. Bartoš, X. Cai, M. Kolovratník. A detection of the coarse water droplets in steam turbines. In EPJ web of conferences, EFM13 - Experimental Fluid Mechanics 2013, vol. 67, p. 02005. 2014. DOI:10.1051/epjconf/20146702005

[5] M. Kolovratník, O. Bartoš. CTU Optical probes for liquid phase detection in the $1000 \mathrm{MW}$ steam turbine. In EPJ Web of Conferences, EFM14 - Experimental Fluid Mechanics 2014, vol. 92, p. 02035. 2015. DOI:10.1051/epjconf/20159202035

[6] M. Kolovratník, J. Hrubý, V. Ždímal, et al. Nanoparticles found in superheated steam: a quantitative analysis of possible heterogeneous condensation nuclei. Proceedings of the Institution of Mechanical Engineers, Part A: Journal of Power and Energy 228(2):186 - 193, 2014. DOI: $10.1177 / 0957650913512816$

[7] L. Měšt'anová, O. Bartoš. A study of the coarse water droplets formation in the nozzle. In EPJ Web of Conferences, EFM18 - Experimental Fluid Mechanics 2018, vol. 213, p. 02058. 2019. DOI:10.1051/epjconf/201921302058.

[8] O. Bartoš, P. Pavlíček, L. Měšt'anová. An experimental study of the coarse droplets formation. In AIP Conference Proceedings, vol. 2189, p. 020002. AIP Publishing LLC, 2019. DOI:10.1063/1.5138614. 
[9] S. Rydblom, B. Thörnberg. Liquid water content and droplet sizing shadowgraph measuring system for wind turbine icing detection. IEEE Sensors Journal

16(8):2714 - 2725, 2016. DOI:10.1109/JSEN.2016.2518653.

[10] W. C. Hinds. Aerosol technology: Properties, Behavior, and Measurement of Airborne Particles. John Wiley, New York, 1999.

[11] N. Otsu. A threshold selection method from gray-level histograms. IEEE transactions on systems, man, and cybernetics 9(1):62 - 66, 1979. DOI:10.1109/TSMC.1979.4310076

[12] T. F. Chan, L. A. Vese. Active contours without edges. IEEE Transactions on image processing 10(2):266 - 277, 2001. DOI:10.1109/83.902291.

[13] T. F. Chan, B. Y. Sandberg, L. A. Vese. Active contours without edges for vector-valued images. Journal of Visual Communication and Image Representation 11(2):130 - 141, 2000. DOI:10.1006/jvci.1999.0442.
[14] R. T. Whitaker. A level-set approach to 3D reconstruction from range data. International journal of computer vision 29(3):203 - 231, 1998. DOI:10.1023/A:1008036829907

[15] M. J. Moore, C. H. Sieverding. Two-phase Steam Flow in Turbines and Separators. McGraw-Hill, 1976.

[16] J. Valha. Proudění mokré páry a její erozivní účinky v průtočné části parní turbíny. In SVUSS, Sborník referátů. 1978.

[17] D. R. Guildenbecher, C. López-Rivera, P. E. Sojka. Secondary atomization, 2009. DOI:10.1007/s00348-008-0593-2

[18] M. Hoznedl, M. Kolovratník, O. Bartoš, et al. Experimental research on the flow at the last stage of a 1090 MW steam turbine. Proceedings of the Institution of Mechanical Engineers, Part A: Journal of Power and Energy 232(5):515 - 524, 2018. DOI: $10.1177 / 0957650917749692$ 


\section{A. Appendix}

\section{A.1. Colour images}

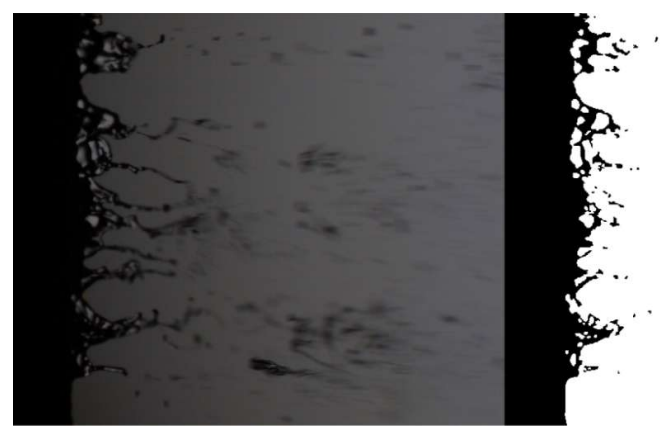

Figure 19. Original (left) and segmented (right) image using GMM-based method.

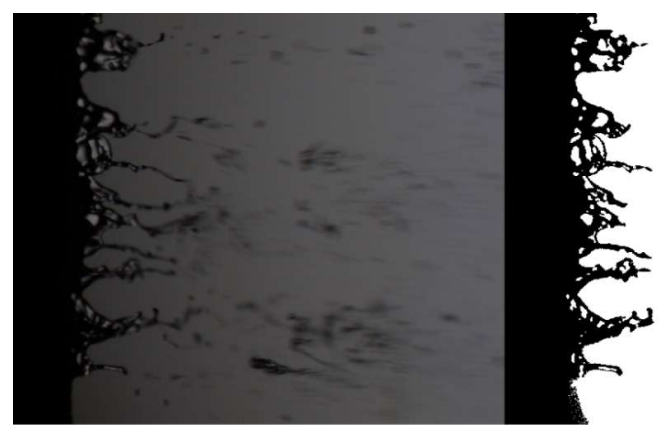

Figure 20. Original (left) and segmented (right) image using active contour method.

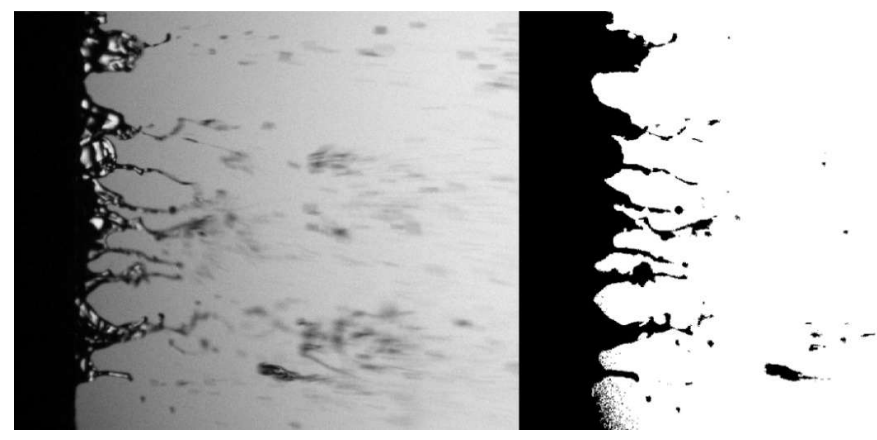

Figure 21. Original (left) and segmented (right) image using Otsu's method.

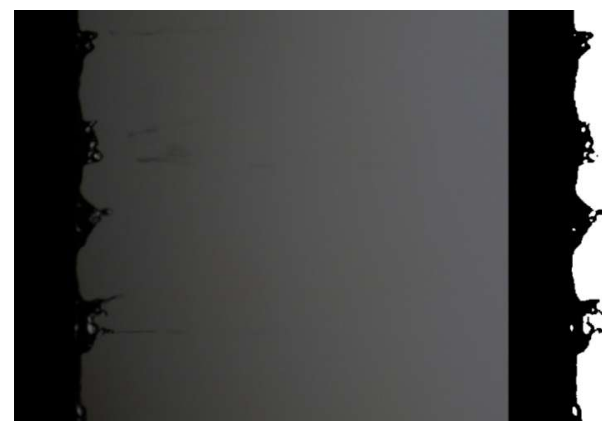

Figure 22. Original (left) and segmented (right) image using GMM-based method. 


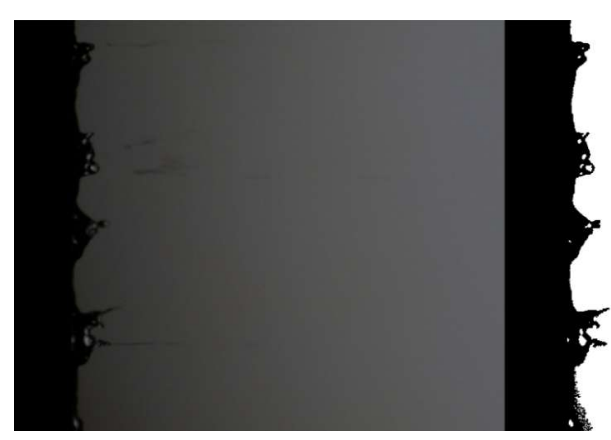

Figure 23. Original (left) and segmented (right) image using active contour method.

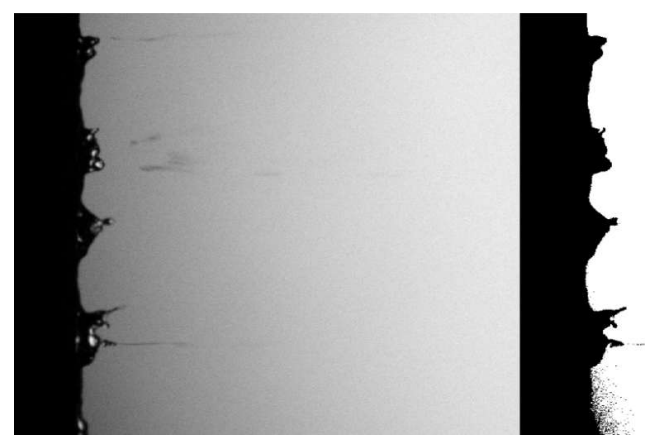

Figure 24. Original (left) and segmented (right) image using Otsu's method.

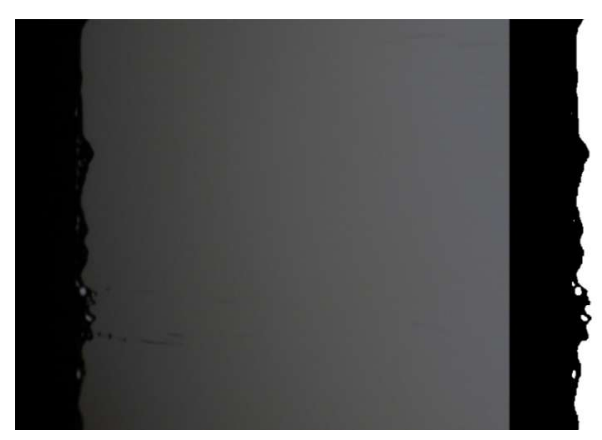

Figure 25. Original (left) and segmented (right) image using GMM-based method.

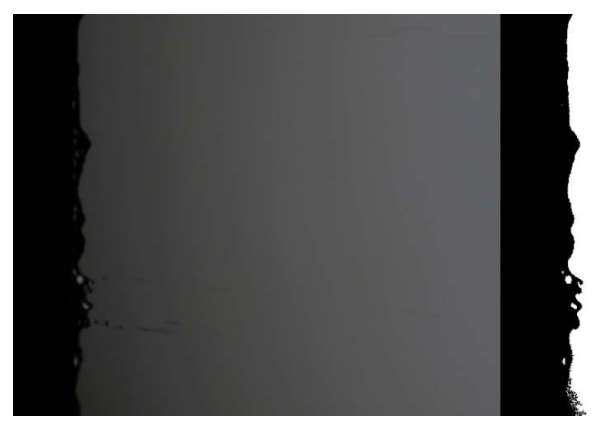

Figure 26. Original (left) and segmented (right) image using active contour method. 


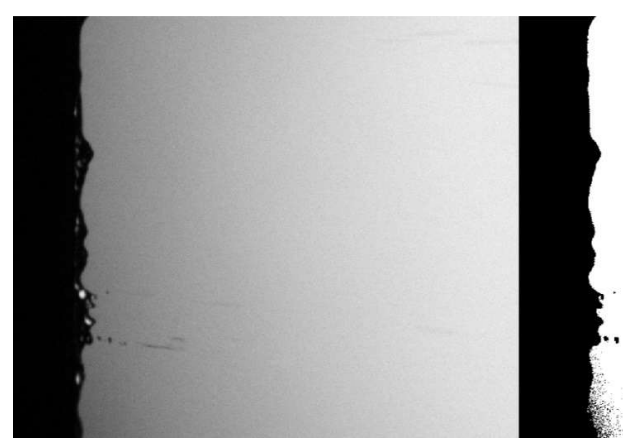

Figure 27. Original (left) and segmented (right) image using Otsu's method.

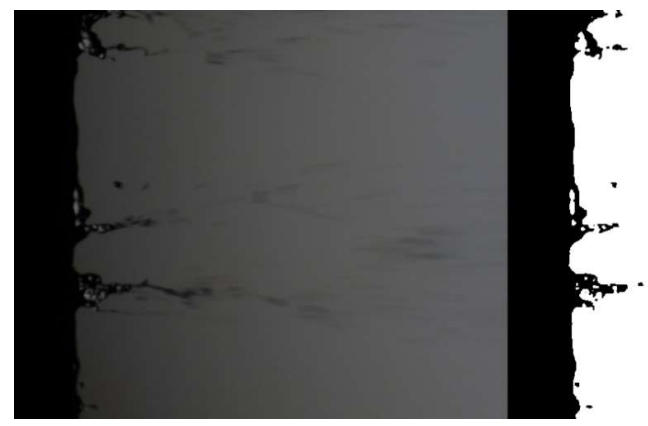

Figure 28. Original (left) and segmented (right) image using GMM-based method.

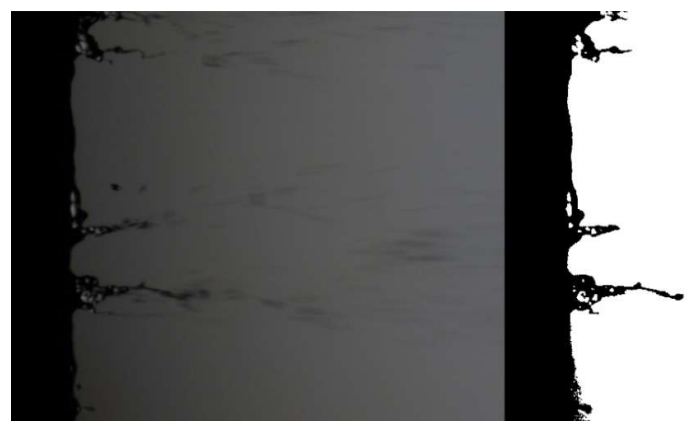

FIGURE 29. Original (left) and segmented (right) image using active contour method.

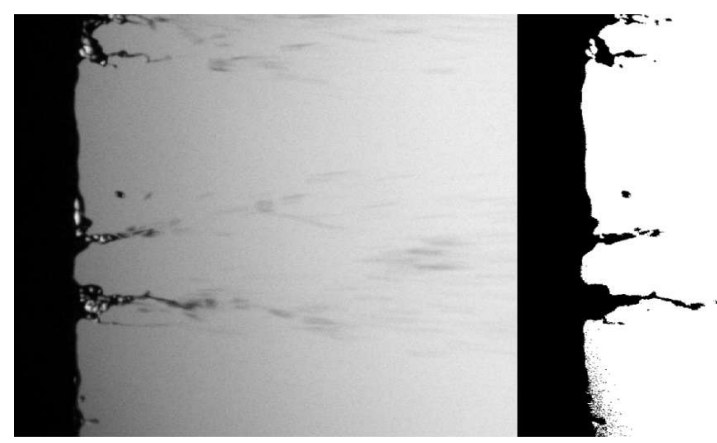

Figure 30. Original (left) and segmented (right) image using Otsu's method. 


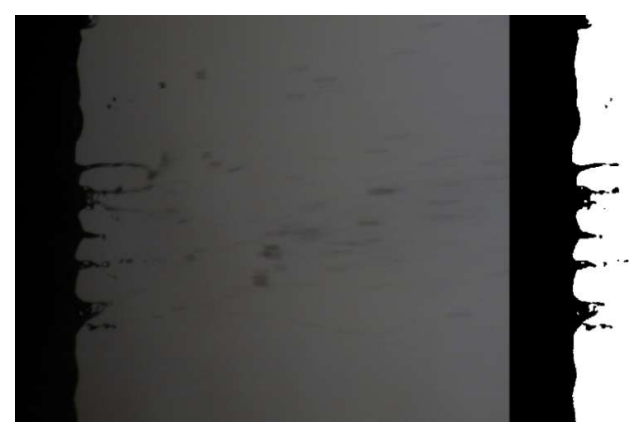

FiguRE 31. Original (left) and segmented (right) image using GMM-based method.

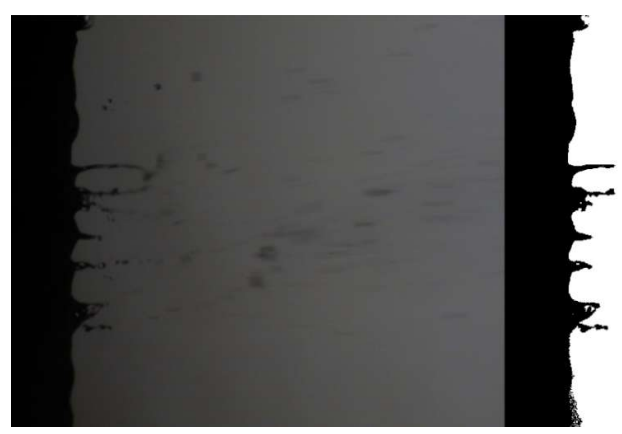

Figure 32. Original (left) and segmented (right) image using active contour method.

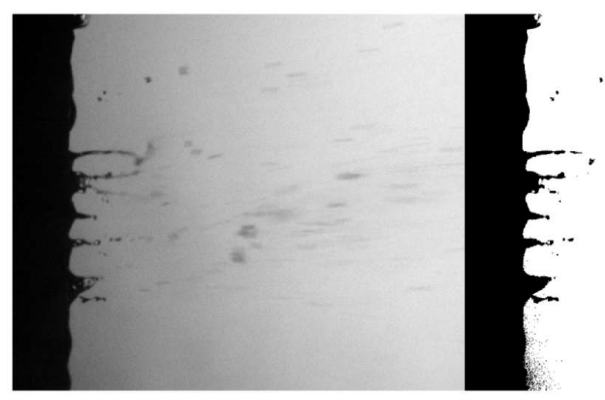

Figure 33. Original (left) and segmented (right) image using Otsu's method. 


\section{A.2. Grayscale images}

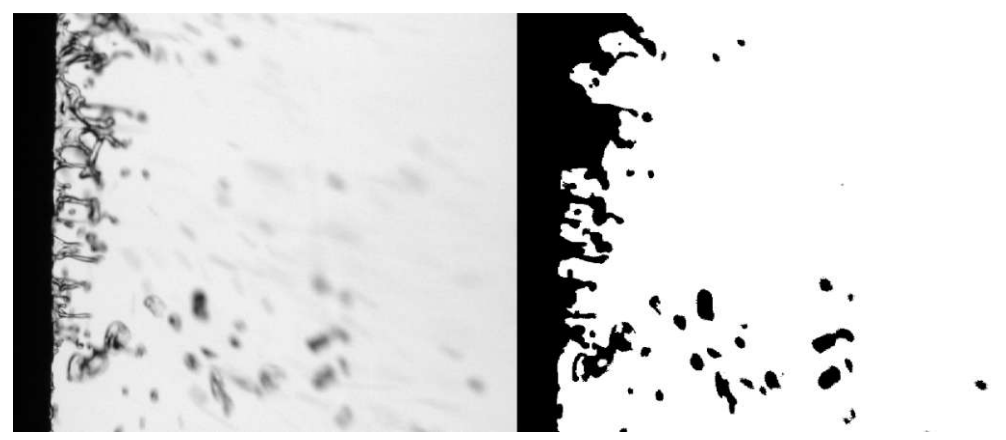

FIGURE 34. Original (left) and segmented (right) image using Otsu's method.

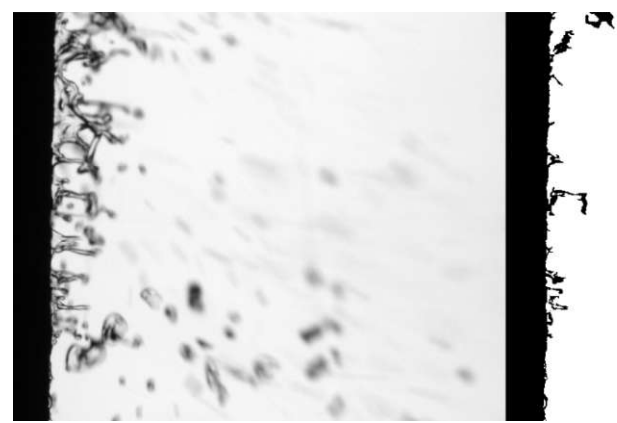

Figure 35. Original (left) and segmented (right) image using active contour method.

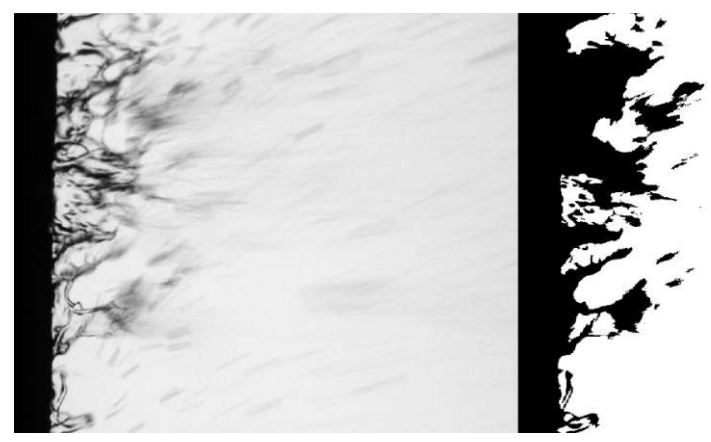

Figure 36. Original (left) and segmented (right) image using Otsu's method.

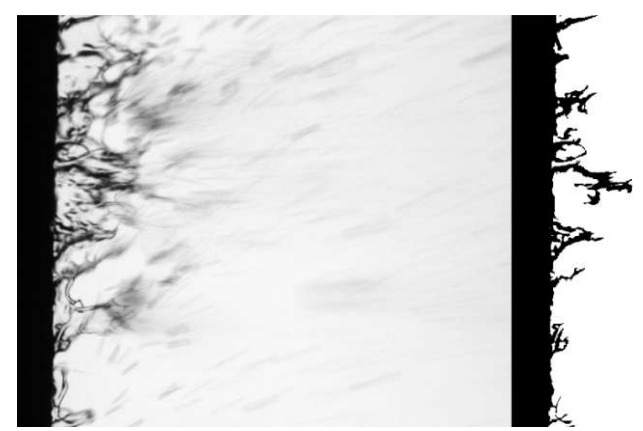

FiguRE 37. Original (left) and segmented (right) image using active contour method. 


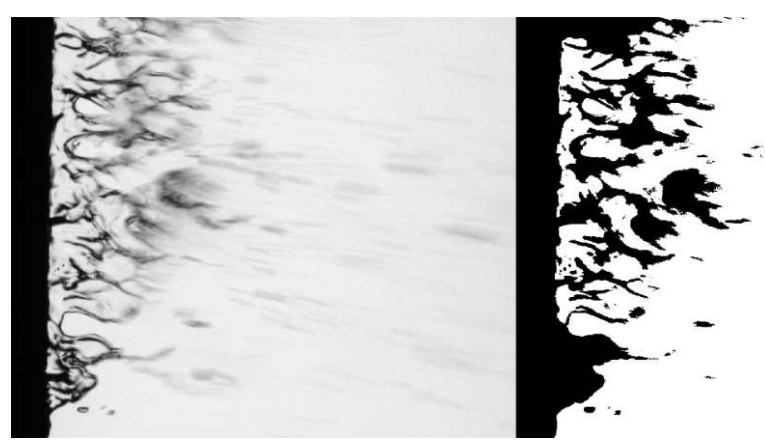

Figure 38. Original (left) and segmented (right) image using Otsu's method.

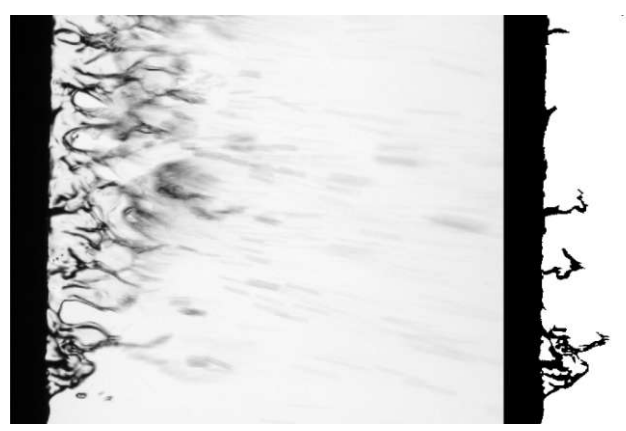

Figure 39. Original (left) and segmented (right) image using active contour method.

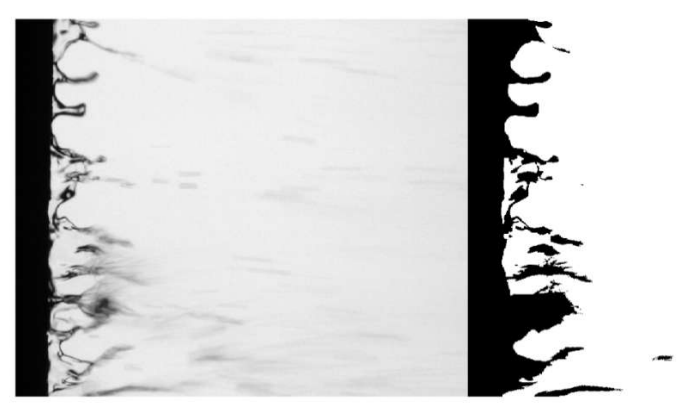

Figure 40. Original (left) and segmented (right) image using Otsu's method.

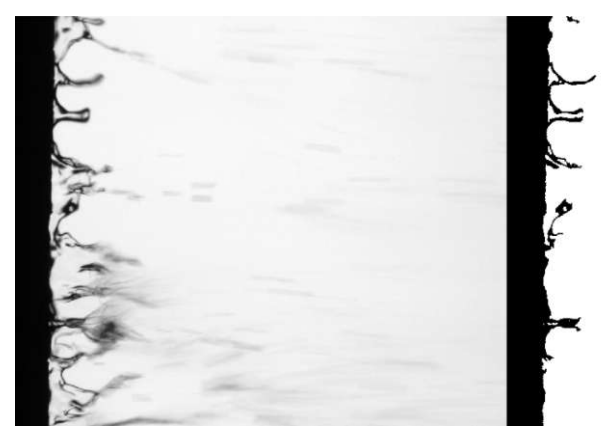

Figure 41. Original (left) and segmented (right) image using active contour method. 


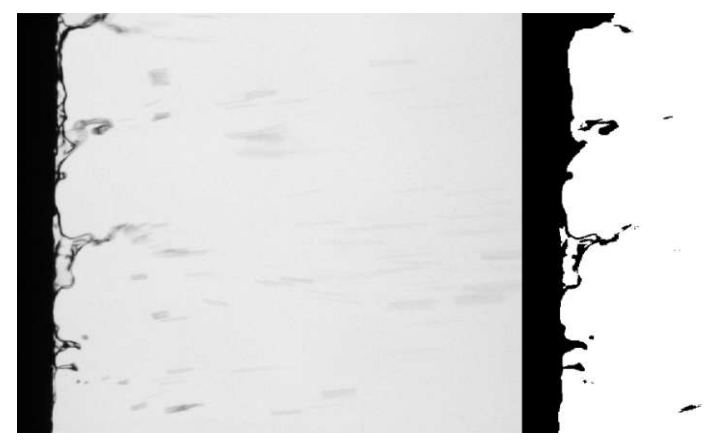

Figure 42. Original (left) and segmented (right) image using Otsu's method.

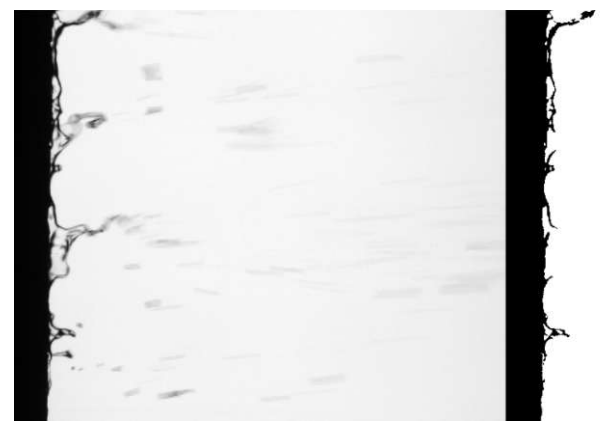

FigURE 43. Original (left) and segmented (right) image using active contour method. 